\title{
The 2009 Match-fixing Incident in Taiwan's Professional Baseball League
}

Authors' contribution:

A) conception and design of the study

B) acquisition of data

C) analysis and interpretation of data

D) manuscript preparation

E) obtaining funding

\author{
Wensheng Wang ${ }^{\text {A-E }}$, Renfu Lo ${ }^{\text {A-E }}$
}

National Taiwan University of Physical Education and Sport, Taiwan

\section{ABSTRACT}

The Chinese Professional Baseball League (CPBL) was the first professional sports league ever created in Taiwan, but has been plagued by a series of match-fixing scandals starting from 1996. However, the 2009 scandal happened to the most popular club, Brother Elephants. The corrupt "Windshield Wiper" ring was the mastermind behind whole affair. Twenty-six former and active players and coaches were involved that put the games' ethics and integrity in jeopardy. In particular, star players such as Cao Jinhui and Chen Zhiyuan were banished from baseball forever, which certainly shocked the public. Accordingly, the CPBL was again on the verge of disbandment. Facing such a crisis, fans organized a street protest and spontaneously demanded that the government take actions against such an adverse environment. Subsequently, the authorities stipulated several plans in order to revive the "national sport" people used to love.

\section{KEYWORDS}

\section{Introduction}

The first gambling scandals involving Taiwan's professional league occurred in 1996 and shocked the baseball league and its fans. Players conspired with gambler contacts by receiving money or other benefits, and intentionally made their own team lose games. So, when a great amount of money is bet for the team to win, people who bet for the team to lose can win tremendous amounts of prize money ( $\mathrm{Fu} \mathrm{1997).} \mathrm{As} \mathrm{a} \mathrm{result,}$ Taiwan's CPBL entered into a dark period. It was not until the 2001 World Cup, during which the Taiwanese national team won the bronze medal, that public confidence and trust in professional baseball was restored. Unfortunately, gambling scandals kept happening from 2005 to 2009. The players' ethics and integrity, as well as the management of professional teams, were in question. The biggest news in 2009 was the illegal activities associated with gambling that occurred in the most popular CPBL team, the Brother Elephants. Up to 26 active and former players were connected with the scandal, which embarrassed the 20-year-old professional league once more, after it had just rekindled the passion of the public by signing several outstanding players who had played in the Major League Baseball (MLB) and Nippon Professional Baseball (NPB).

As one of the founding teams of the CPBL, Brother Elephants is one of the two original teams that still exist today (the other existing team is President Lions) while Weichuan Dragons and Mercury Tigers were disbanded immediately after the first match-fixing scandal. The Elephants have taken part in countless memorable games and fostered many star players for their fans in their glorious 20-year history, during which it mirrored the ups and downs of the league. They have been the most popular baseball team over the 
decades. Why can the Elephants attract such wide range of fan support? Senior anchor Cai Mingli mentioned the "yellow shirt spirit" as the answer, and the "insistence to never-give-up" is the most essential and charming element of that spirit (Cai 2008).

\section{The most popular club in the CPBL}

The Brother baseball team was founded on September 1, 1984. Its sponsor company is Brother Hotel Inc. owned by the Hong brothers. After the hotel business started to get on track, Hong Tenghseng, dubbed the father of the CPBL, began to inquire around with baseball enthusiasm by inviting local enterprises to form the first professional league on the island. His hard work paid off. The preparatory committee recruited business entities including Weichuan Corp., Uni-President Enterprise Corp., and Mercuries \& Associates, eventually founding the CPBL on October 23, 1989. Hong served as the secretary general, and Tang Panpan, the then-president of the Chinese Taipei Baseball Association, was the commissioner (Wang 2004). The first head coach of Brother Hotel was the well-disciplined Zeng Jien, who had been the skipper of Air Force team for nearly 40 years (Yu \& Gao 2010).

The Brother Hotel started to recruit players in August 1984. First of all, a "good moral character" examination was carried out by Hong Tengsheng for the tryout, followed by a skills test by Zeng, the head coach. They established a team motto: "morals decide achievement, practice makes perfect" (Wu 2006), and became one of the few amateur baseball teams run by a private enterprise. The Brother Hotel made many innovations. For instance, in 1985 the team bought a tea farm and re-constructed the land into a simple ballpark where the team would conduct spring training every year before the season began. During the offseason, the field is open to local institutes or amateur teams, providing a vital link that connects baseball and the community.

In addition to the "yellow shirt spirit," Brother intentionally promoted many players to stardom during the professional period when they adopted Elephants as their mascot. Sport marketing specialist Liao Shiyao once mentioned in his book Elephant Fever, "fans are the root of maintaining baseball team, and the key to it is the star players who can draw fans' eyes" (Liao 1995, p.15). First generation stars were "Stealing King" (Lin Yizeng), "Mr. Baseball" (Li Juming), "Weekend Killer" (Chen Yixin), and "Mr. Popular" (Wang Guanghui). Then comes to the next generation stars, such as "Golden Warrior" (Chen Zhiyuan), "Cha-cha" (Peng Zhengmin), and "A-bian" (Cai Fengan). Finally, the current stars are "Golden Submarine" (Liao Yucheng) and "Chairman Cao" (Cao Jinhui). Every one of these star players is one of the most famous ballplayers of their generation that turned Brother Elephants into a well-known brand in Taiwan.

The popularity of the team brought huge opportunity for sponsorship. In 2003, the Elephants were the first baseball team to make profits, accrued from advertising, authorized team products, advertising endorsements, live game promotion sales, etc. The most effective way among these was advertising (Zhang 2005). Aside from the team's box office gross and profits from direct sponsorship, successful operating strategy and cooperation with outside entities helped the team secure sustainable development. Accordingly, Brother Elephants were able to produce their own star players.

From 1992 to 1994 and from 2001 to 2003, the Elephants twice won three consecutive championships, and this record secured the team's position as the most popular team in the CPBL. The league suffered a huge setback after the game-fixing involvement of China Times Eagles and the struggle with the second professional league, Taiwan Major League (also called Naluwan). One reason the CPBL was able to pull through the hard times was because of the fantastic performances by the Taiwanese national team in the 2001 Baseball World Cup. The other reason was that the Elephants played a leading role in the regular season: they ultimately captured the Taiwan Series championship three years in a row ( $\mathrm{Yu}$ 2007). Among the national team that played in the World Cup that year, only Chen Zhiyuan was from the Elephants. That explains how Elephants fans showed huge support for the team, which was also the most essential force to help CPBL survive the darkest period (Shoujuzi 2003). 


\section{The eruption of the scandal}

The first game-fixing scandal of the CPBL was revealed in 1996, and after eight peaceful years, the scandal that severely tarnished the league's image occurred again in 2005. Subsequently, a series of scandals coat-tailed another one. There were scandals of game fixing that involved entire team in 2007 and 2008. The infamous saga of "Black D-media Incident" in 2008 (as most of the corrupted players were from the Dmedia T-REX team) was fortunately offset by the return of talented players stationed abroad. The CPBL was able to shake off the impact of these scandals. However, after the passionate 2010 Taiwan Series, while all fans were still basking in the excitement of an exhilarating season, the prosecution office suddenly dropped a shocking bomb on Taiwan's baseball league. This time, the game fixing involved players from the most popular team, the Brother Elephants.

The prosecution office searched 26 locations and not only caught "Windshield Wiper," Cai Zhengyi, the head of a gambler gang, but also searched the dormitories of Brother Elephants and La New Bears. Former Elephants pitcher Zhuang Youlin (originally named Zhuang Hongliang) and Bears pitcher Huang Junzhong were the main people investigated. CPBL Commissioner Li Wenbin showed his indignation toward the action, and questioned why the investigation started when the season had already finished. The prosecution office responded that "first we thought we might complete the evidence collection; however, the evidence tells of the extensive involvement of this game fixing incident, and therefore we re-started investigation on these four teams, thus delaying our action to interrogate related people till the season was over" (He 2009). Yet the public discredited the prosecution office in 2005 for involving the "Black Bears Incident" (game-fixing scandal of La New Bears players in 2005). At that time, prosecutor Xu Weiyue monitored the gamblers' contact to collect evidence but meanwhile earned gambling money for themselves by utilizing the bugging information. This time, prosecutors collected evidence by bugging, monitoring, and interviewing. As a result, they found the key figures, such as Zhuang Youlin, Huang Junzhong, etc., which exposed the whole game-fixing ring. Within this game fixing arrangement, superstar players like Cao Jinhui and Chen Zhiyuan were difficult to conspire with, so the head "Windshield Wiper", Cai, would show up personally to negotiate with them. At this point, Cao and Chen were still free from being indicted due to lack of evidence, and were not on trial. The game-fixing scandal is the most serious in the CPBL history: it involved many people including politicians, gangsters, former and active players, and even the head coach.

The gambler gang headed by "Windshield Wiper" is an organized criminal group, while the financial supporter behind it remains unknown. Legislator Qiu Yiying speculated that former Tainan councilor Wu Jianbao was deeply involved in the scandal (Yang 2009). Being supported and covered by political power enabled this gambler gang to have strong financial capabilities. Windshield Wiper's chief controller, Huang Renyi, took charge of money flow and account details, and Windshield Wiper utilized the agent to find appropriate former and active players to work as "outside contacts" who knew more about the game tactics and players' thoughts. Therefore, they could easily and effectively find players to conspire with. The main contact person was Zhuang Youlin, a former pitcher for the Elephants. He went on to hobnob with players on the team who were willing to be "inside contacts" to gang up the game fixing. Active players Wang Jinli and $\mathrm{Wu}$ Baoxian agreed to do this job, and both of them went to find more players to fix games. Usually, the pitchers were paid higher to fix the game, because they had more control of the game's outcome. Former Brother Elephants head coach Nakagomi Shin was also involved in this scandal. He deliberately made unreasonable strategies causing the team to lose and set up the game fixing.

\section{Prosecution charges by district attorney}

In the game-fixing scandal of the Brother Elephants, Zhuang Youlin, Huang Junzhong, and Wang Jinli were the main contacts to which the prosecutor paid special attention. By means of long-term investigation, prosecutors looked forward to clarifying total involved persons. Zhuang was even found stocking drugs, though with his confession, his punishment could be reduced. Other players involved in game fixing had deferred prosecutions, and were given from 40 hours to 200 hours of mandatory social service. However, 
these players would face serious punishment from their team. According to the CPBL regulations, Article 21 of the player contract stipulates that a "player who has involved with game-fixing will need to compensate the team double of his contract salary" (Lou, Lan \& Cai 2010). Huang, for example, needed to pay La New Bears more than NTD 20 million (New Taiwanese dollars) for civil compensation. Thereafter, this payment became the biggest burden in Huang's life. As for the Brother Elephants head coach, Nakagomi Shin, a Japanese, was also indicted for deliberately making dubious strategies. He strongly insisted he was under great pressure from Zhuang. However, the truth is that he has become the first head coach in the history of CPBL to be indicted. During the investigation, former Elephants Head Coach Lin Yizeng was also suspected. Due to a lack of evidence, he was not indicted.

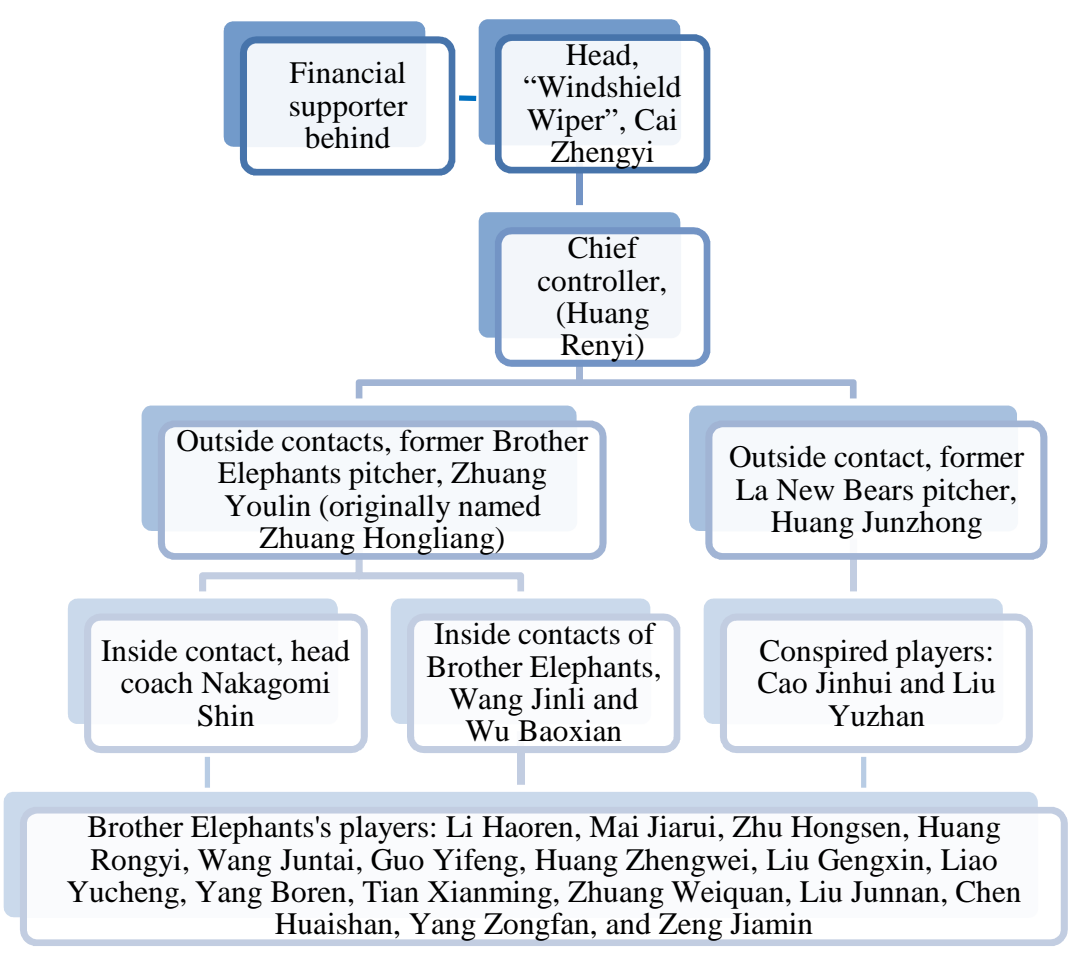

Figure 1. Diagram of gambling conspiracy of the Windshield Wiper ring

The most shocking news was that star players Cao Jinhui and Liao Yucheng were included in this indictment list. Liao, nicknamed "A-Gai", chose to admit his guilt at the first moment, and received deferred prosecution that forced him to be expelled from the professional league forever. It's especially shameful for him who started from scratch and rose to be an ace pitcher. As for Cao, he was the first Taiwanese pitcher to take the mound and win a game in the MLB. Shockingly, the Windshield Wiper head, Cai, had numerous meetings with Cao, whose intention was strongly suspected by the prosecutors. Yet Cao was not indicted either, also because of a lack of evidence. Nevertheless, the owners of the Elephants were angered by his unethical behavior, and expelled him from the team. Cao, once a superstar player climbing up on the peak of his career, disappeared from the baseball world. Another two Elephant players, Cai Fengan and Chen Zhiyuan, were advised by the prosecutor to serve two years in prison. Both of them denied involvement in game fixing, and appealed to higher court. In the end, Cai was suspended from being a head coach in high school while Chen's professional contract was cancelled. Both of them faced the toughest situation of their lives.

The most dramatic of all, Head Coach Nakagomi Shin, who tried to escape back to Japan, was subsequently arrested by Taiwan's customs officials. He was brought to the Banqiao district attorney's office for investigation. Afterwards, he was released on bail of NTD 80,000 and was prosecuted when the investigation closed in 2010. He was accused of fixing five games; he pled guilty and wrote an apology letter to the CPBL. His lawyer said that in his letter he described that he was out of work and could not support his 
family. But he still tried hard to borrow NTD 80,000 and donate it to charitable organizations in a hope that the public could forgive him, allowing him to return to Japan soon. Nakagomi admitted that he had successfully fixed three games while the other two failed, and received NTD 1.5 million as an "honorarium". He hoped his confessions could cancel his ban on leaving the country and return to Japan. For each of the three successfully fixed games, he was given five months imprisonment. As for the remaining two unsuccessful fixing games, he was given three months. In the end, he received one year and eight months of imprisonment, which could be converted into a NTD 1.8 million fine ( $\mathrm{Su} 2010)$.

\section{The aftermath of the scandal}

\section{Drastic decline in attendance}

The outbreak of the scandal directly affected game attendance. Moreover, this time it involved players on the Elephants who were renowned franchise players and had enormous amounts of fans. Would this scandal cause a great decrease in the fan base for the CPBL in the following year? This is a topic for researchers to keep tracking. But look at previous records: game-fixing scandals have all resulted in drastic declines in attendance in following seasons. Not only were famous players indicted for the scandal, but teams faced the crisis of disbandment as well. Therefore, the number of baseball fans has decreased (Weng 2009). Here the authors conclude - as shown in the Table below - the games' attendance figures before and after the game-fixing scandal. (In 2009, games were affected by the game-fixing scandal of D-media: the number of baseball teams shrunk from 6 to 4, and the remaining 58 games were canceled).

Table 1. Attendance statistics in the following year after game-fixing scandal

\begin{tabular}{lccccc}
\hline Season & Year & $\begin{array}{c}\text { Total } \\
\text { games }\end{array}$ & $\begin{array}{c}\text { Total } \\
\text { audience }\end{array}$ & $\begin{array}{c}\text { Average } \\
\text { audience } \\
\text { per game }\end{array}$ & $\begin{array}{c}\text { Growth Rate } \\
\text { (compared with } \\
\text { previous year) }\end{array}$ \\
\hline 1997 & 1997 & 336 & 685,832 & 2,041 & $\boldsymbol{\nabla} 55,12 \%$ \\
2006 & 2006 & 300 & 679,205 & 2,264 & $\boldsymbol{\nabla} 32,67 \%$ \\
2008 & 2008 & 298 & 572,692 & 1,922 & $\boldsymbol{\nabla} 5,93 \%$ \\
2010 & 2010 & 240 & 645,648 & 2,690 & $\boldsymbol{\nabla} 28,11 \%$ \\
\hline
\end{tabular}

Source: http://zxc22.idv.tw/

The game-fixing scandal in 2009 revolved around the Brother Elephants and La New Bears, the teams of the corrupted players. This was also reflected in the loss of their fans. No player from the Uni-President Lions was involved. Consequently, their fan loss was less serious. Fans were heartbroken by the game-fixing scandal and started to call in question the team they supported. As a result, they gradually stopped spending money on game tickets, which impacted the league as a whole.

Table 2. Average attendance for each club in the 2010 CPBL season

\begin{tabular}{lccccc}
\hline Team & $\begin{array}{c}\text { Total } \\
\text { game }\end{array}$ & $\begin{array}{c}\text { Total } \\
\text { audience }\end{array}$ & $\begin{array}{c}\text { Average } \\
\text { audience per } \\
\text { game }\end{array}$ & $\begin{array}{c}\text { Average } \\
\text { audience } \\
\text { in 21 years }\end{array}$ & Growth Rate \\
\hline Brother Elephants & 120 & 381,238 & 3,176 & 4,730 & $\mathbf{\nabla} 32.85 \%$ \\
Uni-President Lions & 120 & 311,630 & 2,596 & 3,257 & $\boldsymbol{\nabla} 20.29 \%$ \\
Sinon Bulls & 120 & 303,620 & 2,530 & 3,487 & $\mathbf{\nabla} 27.44 \%$ \\
La New Bears & 120 & 294,808 & 2,546 & 3,495 & $\boldsymbol{\nabla} 29.73 \%$ \\
\hline
\end{tabular}

Source: http://zxc22.idv.tw/

\section{Player exodus for lower signing bonus}

A series of match-fixing scandals have resulted in a lack of confidence in Taiwan's professional league from players in younger generations. As baseball becomes more and more globalized, the MLB has 
been scouting young players in Taiwan. Homegrown talent may therefore sign with an MLB club for low signing bonuses instead of staying in Taiwan. The CPBL even attempted to curb the outflow by planning to ban those players whose signing bonuses offered by overseas club were under NTD 200,000 (Lin 2008). Since the domestic environment is so bad, many young players gave up joining the CPBL and chose to go to America or Japan (Yu \& Wang 2009). The loss of talented players leads to weak competition in the domestic league; therefore, the game's quality deteriorates.

Professional leagues in America and Japan offer comprehensive welfare programs to their players on and off the field. A famous Taiwanese pitcher in the MLB, Wang Jianmin (Wang Chien-ming), said that when he plays games with the team, he always has an attendant with him, so he will not need to worry about unnecessary disturbances and can concentrate sorely on the game. However, players in Taiwan are not so lucky. Former Cobras outfielder Zhou Siqi (now playing for the Elephants) was once coerced to a motel by gangsters and threatened for not collaborating with them (Lou 2008). Terrifying incidents like this makes people wonder about parents' willingness to allow their children to join this life-threatening environment. This is especially true for Taiwan, which is a typical anti-physical Chinese society deeply influenced by Confucianism and which values scholarly pursuits and despises manual labor (Yu \& Bairner 2011).

\section{Government involvement in the CPBL}

After Taiwan's national baseball team lost to archrival China twice - in the 2008 Olympics and the 2009 World Baseball Classic - the government established the Baseball Revival Committee, and proposed many "Baseball Revival Plans" that were intended to show support for baseball and to rejuvenate the "national sport." In addition to subsidies, it also encouraged city and county governments to organize teams. But the plans did not include the CPBL, which is regarded as a commercial activity. After CPBL's 20th year, the Brother Elephants, which had had a great influence in the CPBL, were exposed for being involved in the game-fixing scandal. The press and public would all agree that if Brother Elephants were to be dismissed, the entire CPBL would collapse completely. After the scandal, baseball fans protested on the street in the hope that the government would put massive resources into the sport. This was also the first time the fans organized to protest spontaneously against the corruption (Chen 2009). The government finally discovered the gravity of the situation and responded to the fans' wishes. As a result, it enacted "Professional Baseball Revival Plans". The three main pillars of the plan are as follows:

First, supporting professional clubs set up minor league teams. In order to support the minor league teams for four clubs, the government will subsidize each team NTD 10 million.

Second, strengthening CPBL's home-away facilities. Brother Elephants adopts Tianmu and Xinzhuang field, Uni-President adopts Tainan field, Sinon adopts Taichung field, and La New adopts the one in Chengqing Lake. The Sports Affairs council will cover the expenses of maintaining and running the ballparks.

Third, issuing preventive measures against fixing matches. Involved players are given a quick indictment and stiffer penalties and are also banished not only from the league but also holding any teaching job in a school. Legislator Chen Shuhui suggested that the government should ask schools to "include watch CPBL games as part of extracurricular physical education" so as to boost game attendance, which plummeted after the game-fixing scandal. This suggestion is supported by the Ministry of Education and Sports Affairs Council (Du 2010).

\section{Conclusion}

Starting from Japanese rules, baseball has been imbued with national pride in Taiwan for over a century. According to Lin (2006), "Baseball is one of the top sports in Taiwan with most strength and influence". Now the most-watched sport in Taiwan is facing its biggest crisis ever. Reviewing the history of game-fixing scandals, gangsters kidnapped Brother Elephants players and forced them to fix the game in 
1996. Players were in the middle of a "money-or-bullet" scenario (Miguo 2006). If they did not agree to receive money and throw the game, they were threatened with violence by the gangsters. As soon as the scandals were discovered, the players involved were punished and forever expelled from the ball games; the gangsters received several years of imprisonment. However, these convicted gangsters would eventually be released, and could come back to haunt baseball once again. It can be unfair to blame the vulnerable players, since the government does not give enough effort into protecting them. Besides, according to Taiwan's particular cultural background, the ruling partly relies on gangsters to win elections as well (Chin 2003, Yu 2007).

On the contrary, the 2010 Brother Elephants scandal revealed that players were willing to collude with the gamblers to earn easy money without being under duress. These players are shameful for those fans that support them and who spend money on their merchandise; they also bring disgrace to their professional ethics. Damage has been done to Taiwan's baseball, tangibly or intangibly, that will certainly leave deep scars with avid fans. This article hopes to analyze the history and repercussions of the incident in order to provide succeeding researchers with some insights for future developments. The criminal element has already infiltrated Taiwan's most popular team. If the league and government do not make iron-fist policies to change and improve the crooked system, it is possible that professional baseball will disappear for good from the island. Given the status of baseball as Taiwan's national sport, there is a long way to go for the government to repair the fragile baseball environment, plagued by a series of scandals.

\section{REFERENCES}

Cai, M. (2008). Aiguo zhubo bangqiu meng /The baseball dream of a patriotic anchorl. Taipei: Gaobao guoji.

Chen, P. (2009, November 1). Woai bangqiu! Xiang buyao dao! Qiumi shang jietou jiuchu heidao /I love baseball! Don't disband the Elephants! Fans on streets to get rid of the gangsters/. Lianhe wanbao /United Evening News/, A2.

Chin, K.L. (2003). Heijin: Organized crime, business, and politics in Taiwan. London: M.E. Sharpe.

Du, L. (2010, April 23). Liwei chen shuhui juban guanshang zhibang bisai lieru huwai jiaoxue gongting hui /Legislator Chen Shuhui held a hearing on professional baseball games to be included in outdoor teaching curriculum/. Yitu xinwen /E2 News/, retrieved 2010 May 30 from, http://news.e2.com.tw/utf-8/2010-4/1315523.htm

Fu, Z. (1997). Jingbao zhibang heimu /Expose the dark sides of professional baseball/. Taipei: Shangzhi wenhua.

He, X. (2009, October 27). Jiaqiu jituan cong 3 yue jiu kaishi reshen /The match-fixing ring started to warm up in March/. Lianhe wanbao /United Evening News/, A2.

Liao, S. (1995). Huangchao /The yellow tidel. Taipei: Yeqiu ren.

Lin, D. (2006). Cong jianong kan rizhi shiqi taiwan bangqiu yundong de fanzhan /The study of baseball development during Japanese rule through the Jianong team/. Taiwan shiliao yanjiu /Taiwan Historical Materials Studies/, 28, 67111.

Lin, S. (2008, September 12). Luwai xiaojiang kan faguo fazhan menkan /Overseas young players looks at the requirements for returning home/. Ziyou shibao, retrieved 2010 April 27 from, http://www.libertytimes.com.tw/2008/ new/sep/12/today-sp3.htm

Lou, J. (2008, December 24). Juda fangshui qiu zhou siqi zhengji rizi nanguo /Refusing to throw games, Zhou Siqi was subdued for an entire season/. Lianhe bao /United Daily/, AA3.

Lou, J., Lan, Z., and Cai, Z. (2010, February 11). Shean renshu duo xiongdi xiang qiuchang zhibi yiyuan /Involved players increasing, Brother Elephants asks for millions of dollars of compensation/. Lianhe bao /United Daily/, A5.

Miguo (2006). Wanquan ranshao bangqiu buluo /Complete combustion, baseball village/. Taipei: Xiangying wenhua.

Shoujuzi (2003). Canlan de qiuji /The splendid baseball season/. Taipei: Lianhe wenxue.

$\mathrm{Su}$, W. (2010, December 17). Zhishi da jiaqiu zhongru shen pan yinian ban /Instructed to fix games, Nakagomi Shin sentenced to one year and eight months/. Lianhe bao /United Daily/, B1.

Wang, H. (2004). Feixiang 20 nian xiongdi ganen jishi /The twenty years of flying elephants: Records of gratification from Brother/. Taipei: Minsheng bao.

Weng, Z. (2009). Zhonghua zhibang guanzhong renshu yingxiang yinsu zhi tantao/The research of factors affecting Chinese Professional Baseball League's attendances/. Changrong yundong xiuxian xuekan /Chang Jung Journal of Sport and Leisurel, 6, 24-33. 
Wu, J. (2006). Taiwan xiongdi xiang zhibang gean yanjiu /The case study of Taiwan's Brother Elephants baseball club/. Dazhuan tiyu /The University Physical Education and Sports/, 85, 79-85.

Yang, X. (2009, October 30). Qiu yiying dianming yushua de laoban /Qiu Yiying points finger at windshield wiper's boss/. Lianhe bao /United Daily/, A3.

Yu, J. (2007). Playing in isolation: the history of baseball in Taiwan. Lincoln, NE: University of Nebraska Press.

Yu, J., and Bairner, A. (2011). The Confucian legacy and its implications for physical education in Taiwan. European Physical Education Review, 17(2), 219-230.

Yu, J., and Gao, K. (2010). Guojun bangqiu shi yanjiu yi kongjun bangqiu dui de huangji qi weili 1969-1972/The research of baseball history in the military: The case study of the golden period of the Air Force team during 1969 and 1972/. Jingji yundong /Athletics and Sports/, 12(1), 10-24.

Yu, J., and Wang, W. (2009). Bangqiu quanqiu hua dui taiwan de bangqiu chanye he qiuyuan wailiu zhi chongji /The impact of baseball globalization on Taiwan's baseball industry and player exodus/. Guomin tiyu jikan /National Sports Quarterly/, 38(2), 54-59.

Zhang, J. (2005). 2004 nian zhonghua zhibang xiongdi xiang zanzhu shang zhi cuxiao fangshi chutan /The preliminary analysis of sponsors' tactics through Brother Elephants in 2004/. Dazhuan tiyu /The University Physical Education and Sports/, 78, 50-57.

AUTHOR'S ADDRESS:

Wensheng Wang

National Taiwan University of Physical Education and Sport

Department of Recreational Sports Management

No. 16, Section 1, Shuang-Shih Road Taichung

Taiwan, 404

Email: seifer1029w@yahoo.com.tw 